\title{
Abortion history and its association with current use of modern contraceptive methods in Luanda, Angola
}

\author{
This article was published in the following Dove Press journal:
} Open Access Journal of Contraception

\author{
Natalie Morris \\ Ndola Prata \\ Bixby Center for Population, Health \\ and Sustainability, School of Public \\ Health, University of California, \\ Berkeley, CA, USA
}

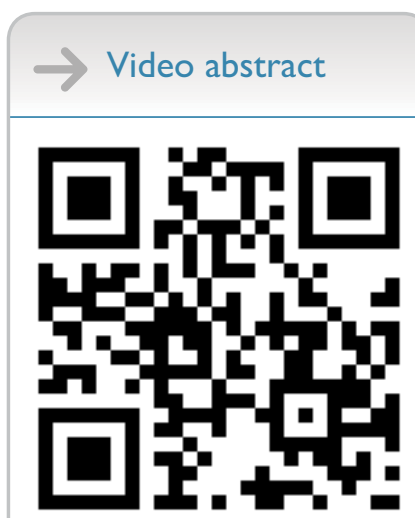

Point your SmartPhone at the code above. If you have a QR code reader the video abstract will appear. Or use: http://youtu.be/BQR3kGhz-M
Background: Women in sub-Saharan Africa often use abortion as a method of limiting their fertility and spacing births. However, it is not well understood whether having an abortion influences contraceptive behavior. The goal of this study was to examine associations between abortion history and use of a modern contraceptive method among women in Luanda, Angola. Materials and methods: We analyzed data on 1,176 women aged 15-49 years from a 2012 cross-sectional study conducted in Luanda, Angola, which aimed to obtain general information on sexual and reproductive health indicators. The outcome and exposure were based on participant reports of past induced abortions and current use of a modern method. We used a modified Poisson regression with robust standard errors to estimate the relative risks of using a modern contraceptive method, given history of induced abortion.

Results: Among all respondents, 736 (62.6\%) reported using a modern contraceptive method. The clear majority of the respondents $(73.21 \%)$, regardless of abortion history, were using either no method, a traditional method, or condoms. Long-acting reversible contraceptive use was very low across all respondents $(2.73 \%)$. The most common family planning method reported by women with a history of abortion was condoms (32.76\%). Regression analysis demonstrated that women who had a history of abortion were 1.23 times more likely to use a modern contraceptive method as compared to those who never had an abortion (relative risk: $1.23 ; 95 \% \mathrm{CI}$ : 1.10-1.36), after adjusting for potential confounders. Postregression estimations of predicted probabilities demonstrated that women with a history of abortion had an $80 \%$ probability of using a modern method ( $95 \%$ CI: $0.76-0.84)$, while those who never had an abortion had a $60 \%$ probability of using a modern method (95\% CI: 0.59-0.61).

Conclusion: History of induced abortion was associated with use of a modern contraceptive method in our study population. The most common contraceptive used by women with a history of induced abortion was condoms, indicating that despite adoption of a modern method, many women are still at risk for an unintended pregnancy. Further research is needed to understand the causal factors underlying women's postabortion contraceptive choices.

Keywords: Angola, abortion, contraception, reproductive health

\section{Background}

Women are often motivated to use contraception after terminating a pregnancy in order to prevent future unwanted pregnancies and subsequent abortions. ${ }^{1,2}$ However, various socioeconomic factors and access to family planning (FP) ultimately influence women's contraceptive behavior, regardless of their history of induced abortion. ${ }^{3,4}$ Understanding the relationship between induced abortion and contraceptive use is an important first step in addressing contraceptive unmet need and gaps in access to FP services.
Bixby Center for Population, Health and Sustainability, School of Public Health, University of California,

42I University Hall, Berkeley, CA, USA

Tel +I 5106434284

Email ndola@berkeley.edu 
Research on FP in sub-Saharan Africa (SSA) suggests that many women use abortion as their primary method of FP, sometimes instead of other contraceptive methods. ${ }^{5}$ When abortion policies are extremely restrictive and access to contraceptive methods is similarly limited, terminating pregnancies is often not a safe procedure; it is estimated that unsafe abortions account for $13 \%$ of maternal deaths in SSA. ${ }^{5,6}$ Furthermore, studies from Europe, Asia, and Africa have shown that a key predictor of induced abortion is having previously terminated a pregnancy, indicating women are likely not getting access to modern methods after their first abortion to prevent another unwanted pregnancy. ${ }^{7,8}$

Other studies have demonstrated that having an abortion may, in fact, lead to increased use of contraception. ${ }^{2}$ Postabortion care (PAC) is intended to be legally available to all women, regardless of a country's abortion policies, and research on postabortion contraceptive behavior suggests that women are more likely to use a modern contraceptive method after an abortion if PAC services are offered..$^{9,10}$ The mixed evidence from these studies indicates a need for additional research to better understand whether women who have induced abortions in places where it is not widely available are getting the services they need to prevent future unintended pregnancies and repeat abortions.

Despite some improvements in contraceptive uptake and reduction of unintended pregnancies over the past 15 years, contraceptive prevalence remains low in SSA, particularly in the country of Angola. ${ }^{11}$ It is estimated that only about $13 \%$ of married women of reproductive age nationwide and $23 \%$ of married women in the capital province of Luanda use a modern contraceptive method, as compared to the regional SSA estimate of $26 \% .{ }^{11,12}$ The countrywide unmet need for contraception is 38\%, while urban centers in Angola have an unmet need of $26 \% .{ }^{12}$ It is imperative to understand the various factors that contribute to modern contraceptive uptake in order to reduce the high levels of unmet need.

There is no up-to-date data available on abortion in Angola, in part due to the fact that induced abortion is only permitted in instances when the woman's life is in danger. ${ }^{13}$ As a result, there have been no recent studies focusing on the contraceptive behaviors of Angolan women who have had induced abortions. Only one study conducted in 1996 examined this relationship, but primarily explored the influence of common social indicators on the use of each type of contraceptive method. ${ }^{3}$ More recent data from Luanda suggest that women in Angola are facing limited contraceptive choices, which may affect postabortion contraceptive uptake. ${ }^{14}$ Understanding the relationship between induced abortion history and contraceptive use is imperative to meeting the high levels of unmet contraceptive need and improving the state of FP services in the country.

The aim of the present study was to investigate the relationship between history of induced abortion and current use of a modern contraceptive method among women in Luanda, Angola.

\section{Materials and methods Sampling and data collection}

The data used for this analysis were obtained from a crosssectional study conducted in Luanda, Angola in 2012. The University of California, Berkeley Bixby Center for Population, Health and Sustainability collaborated with Population Services International (PSI) to implement a baseline survey of sexual and reproductive health behaviors of women in the province of Luanda. At the time of the study, this province encompassed nine municipalities including the capital city of Angola. Two of the nine municipalities were rural communities, while the other seven were urban.

We utilized a multistage random sampling design to ensure that we captured a representative sample of women of reproductive age from all municipalities in Luanda province. The size of the entire population of Luanda was estimated to be 4,901,919 in 2012, according to the National Institute of Statistics. ${ }^{15}$ Power calculations determined the sample size estimates based on municipality population size. We first distributed the target sample size proportionally to the size of each municipality and then randomly selected a number of "sampling points" (churches, hospitals, gas stations, and so on) in each municipality from a list created for that purpose. The number of sampling points chosen per municipality varied according to the total population size in each of the municipalities. Eligible study participants included women aged 15-49 years who resided in Luanda between October and November 2012. A fixed number of participants were randomly selected for recruitment from each sampling point, and one woman from each household was interviewed in order to avoid overrepresentation of women in highly similar environments and life circumstances. In total, 1,825 women of reproductive age living in Luanda were randomly selected to participate in the survey between October and November of 2012 . Of these 1,825 respondents, $85 \%$ completed the survey, $8 \%$ started but did not complete the survey, $6 \%$ refused to participate, and $2 \%$ did not participate due to other reasons.

The Bixby Center and PSI Angola partnered with Sistemas de Informação Industriais e Consultoria, a local marketing firm, to collect the questionnaire data. A multistage 
random sampling design was implemented to capture a representative sample of women of reproductive age from the Luanda province. The data collection tool was developed by researchers at the Bixby Center and drew from the Women's Questionnaire of the Demographic and Health Surveys and Angola's Malaria Indicatory Survey. ${ }^{16}$ The final tool also included additional standardized questions from the PSI Tracking Results Continuously survey tools. ${ }^{17}$ The questionnaire was designed to capture information on women's knowledge, attitudes, and practices related to childbearing and FP in the region. In addition, women were asked about their experiences and preferences with FP service provision and delivery. Sociodemographic and economic indicators were also recorded. All data were collected through selfreport, and interviewers were instructed not to lead or guide the respondent while she answered the questionnaire. The data collection tool was initially written in English and translated to Portuguese by the research team, with feedback from PSI Angola. The research team conducted a pilot test of the questionnaire with 30 women of reproductive age in Luanda. Feedback from this initial round was incorporated into the final Portuguese version, which was later back translated into English. The ethical boards involved in this study approved the procedure of consent, which required all women who agreed to participate to provide verbal consent prior to the interview and for the interviewer to sign to confirm that consent was given. The ethics committees also waived parental consent for adolescent participants; respondents aged 15-17 were not required to obtain parental consent for the study and instead provided verbal assent to participate. Ethical approval for this study was provided by the University of California, Berkeley Committee for Protection of Human Subjects (CPHS \# 2011-08-3521), as well as the Ethical Committee at the Instituto de Saude Publica in Luanda, Angola.

Based on our predetermined exclusion criteria, respondents were dropped from the analysis if they did not complete the survey $(n=280)$ or were not at risk of the outcome, meaning they would not be using a contraceptive method. This included women who were not sexually active $(n=129)$, were pregnant at the time of the study $(n=123)$, were actively trying to get pregnant $(n=32)$, or were infecund or sterilized $(n=69)$. We excluded respondents who did not answer all questions for which variables were constructed for this analysis $(n=16)$. It was possible to utilize complete case analysis because these excluded respondents accounted for $<10 \%$ (1.35\%) of the final 1,192 respondents who were eligible for the analysis. Women who reported wanting another pregnancy at any point in the future were included the study since they may have been using a contraceptive method at the time they were interviewed to space their births. The final sample size used in the analysis was 1,176 .

\section{Variables}

The dependent variable of interest was the type of contraceptive method the respondent reported using at the time of the study. Each participant reported using one of the following methods: intrauterine device (IUD), implant, injectable, pill, condom, traditional methods (rhythm, lactational amenorrhea method, or withdrawal), or no method. In cases where multiple contraceptive methods were listed, the participant was categorized into the most effective method she reported using. The final outcome variable was then collapsed and coded as a binary variable for modern methods or traditional/no method. Modern contraceptive methods were defined as contraceptive devices or medications used to prevent pregnancy, and thereby included the condom, pill, injectable, implant, and IUD. ${ }^{18}$ The primary independent variable, abortion history, collected self-reported information on each respondent's total lifetime number of induced abortions. The questionnaire asked the respondents who had ever been pregnant, "Have you or anyone else voluntarily interrupted any of your pregnancies?" and followed up with how many and in which year these induced abortions took place. The final variable was coded as "no abortions" and "one or more abortions". The primary analysis grouped women who reported having a single abortion with those who had multiple procedures due to the rarity of the exposure in our study sample $(9.94 \%)$. Additional study variables were constructed and included in the fully adjusted model based on evidence from the literature indicating their role as potential confounders in the study relationship. Sociodemographic and individual factors included age, marital status, education, number of living children, and wealth. The final wealth variable was divided into quintiles and constructed with principal components analysis (PCA) using the standard PSI toolkit for creating wealth indices. ${ }^{19}$ The questionnaire also asked the respondents, "Do you believe contraceptives are accessible to you?", which was measured as a binary "yes" or "no" variable based on the respondent's perception of her access to contraceptive methods. Variables for contraceptive self-efficacy, knowledge of contraceptive methods, and community perceptions around FP were constructed using PCA following the PSI PCA toolkit guidelines. ${ }^{20}$ For contraceptive self-efficacy, data were collected for a predetermined list of indicators that measured capability of using contraceptives, ability 
to use methods correctly and consistently to space births, communicate about preventing pregnancy, and negotiate contraceptive use in the face of husband or partner opposition. Knowledge of contraceptive methods was measured through a predetermined set of indicators pertaining to respondents' knowledge of different types of contraceptive methods, including proper use and side effects. Respondents were asked to list all modern contraceptive methods they knew, how they used their own prescribed method, and common side effects of their prescribed method. Finally, the variable for community perception was created using 26 questions in a five-point Likert scale format to determine community acceptability of FP use. Respondents answered questions on whether they were able to discuss FP and contraceptive use with various community members, who included partners, siblings, parents, in-laws, religious leaders, and friends. Response options ranged from "completely disagree" to "completely agree", which were later recoded as "agree/ disagree" binary variables for the PCA.

\section{Statistical analysis}

We examined descriptive statistics to explore dependent and independent variables of interest. Bivariate analysis using chi-square tests assessed differences across the proportions of women who used a modern contraceptive method by induced abortion history and by each covariate included in the adjusted model.

We used a Poisson regression with robust standard errors to approximate the relative risk (RR) of using a modern method among women who had at least one abortion compared to those who had no abortions. A logistic regression would likely have resulted in inflated measures of association because the outcome was common in the study population (21.5\%). A log-binomial model was initially used to fit the data; but due to a lack of convergence, we used a Poisson model with robust standard errors in order to estimate RR. ${ }^{21}$

Models were constructed a priori based on findings from the background literature and variables for which we had collected data. The final, fully adjusted model included all potential confounders for which we had collected information: age, marital status, access, knowledge, wealth, education, community perception, and contraceptive self-efficacy.

Postmodel estimations of predicted probabilities for abortion history were calculated to determine the probability of use of a modern method among women who had zero abortions and among those who had one or more. Statistical significance was set at a cutoff value of $p<0.05$. All analyses were done in Stata $14 .^{22}$

\section{Results}

Figure 1 shows the frequency and percentage of induced abortions for each year that the respondents reported having an abortion. While some induced abortions took place over 20 years before the survey, two-thirds $(66 \%)$ of all induced abortions occurred within the 5 years preceding the survey.

Table 1 presents all the independent variables by the contraceptive method each respondent reported using at the time of the survey. Of the 1,176 women included in the final analytical sample, only $116(9.86 \%)$ women reported having had one or more induced abortions. Bivariate analysis demonstrated a statistically significant difference across one or more contraceptive categories for all covariates $(p<0.05)$.

The clear majority (73.21\%) of all study participants, regardless of abortion history, were using either no method,

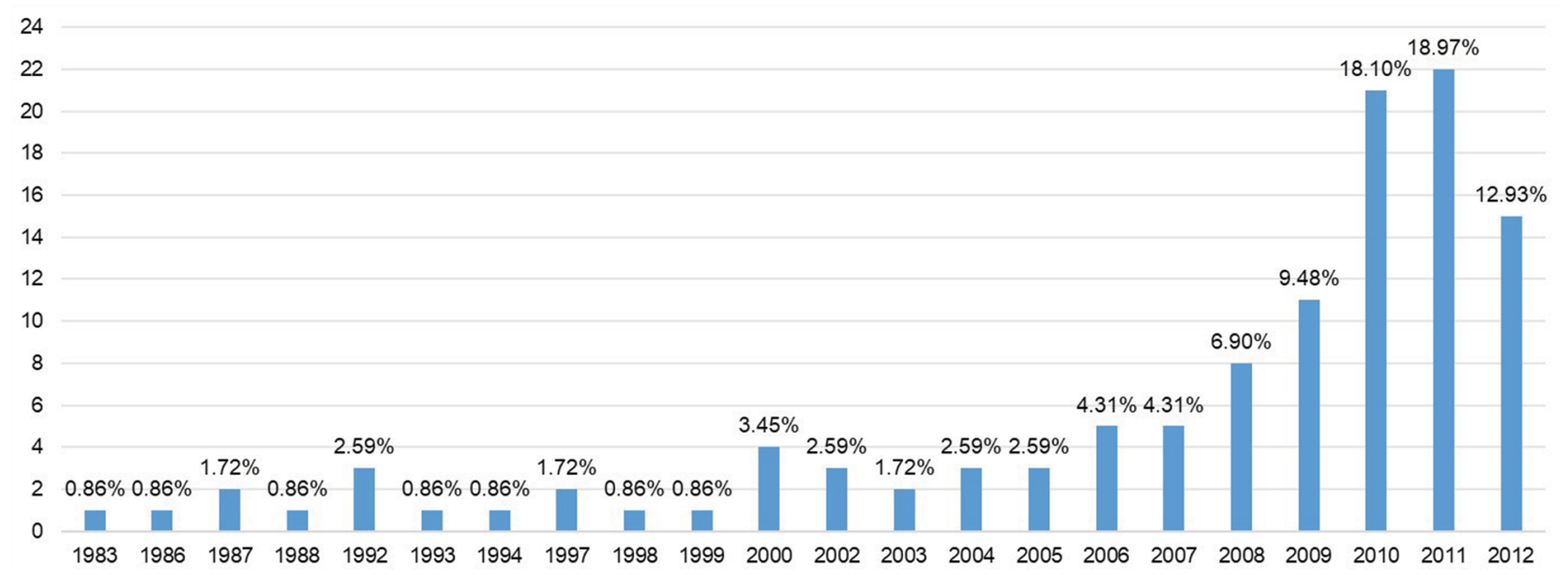

Figure I Frequency and percentage of induced abortion by year. 


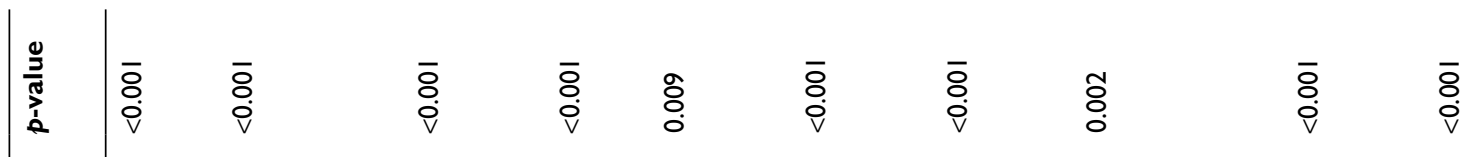

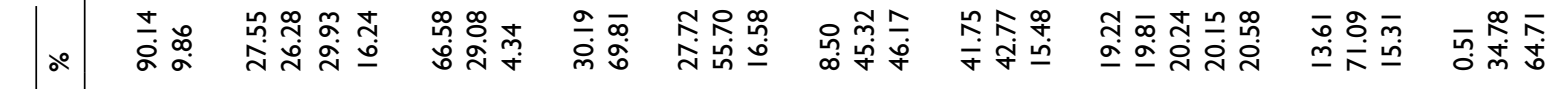

$\stackrel{\circ}{\circ}$

tัน

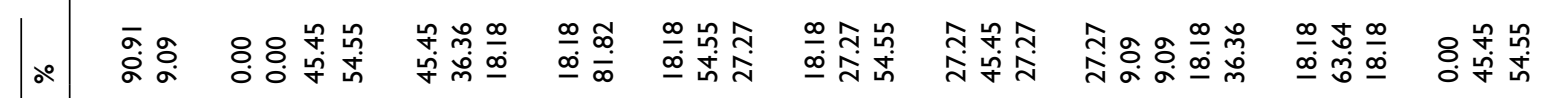

ำ

으

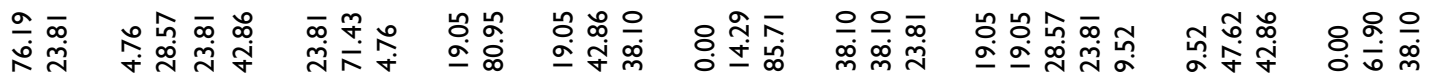

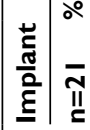

느 $\quad-6$ in $\alpha$ in 느-

ㅁำ

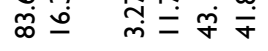

ஸें

更

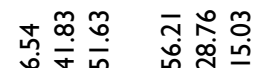

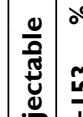

$\stackrel{\underline{\underline{E}}}{\underline{\underline{E}}} \stackrel{\mathrm{II}}{=}$

$\stackrel{\infty}{\simeq}$

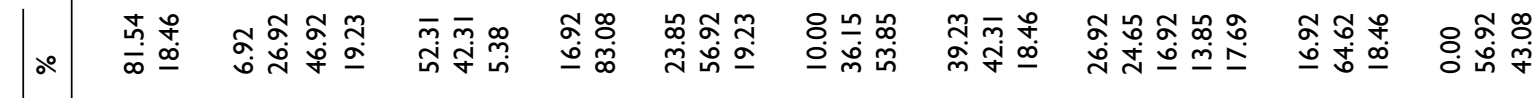

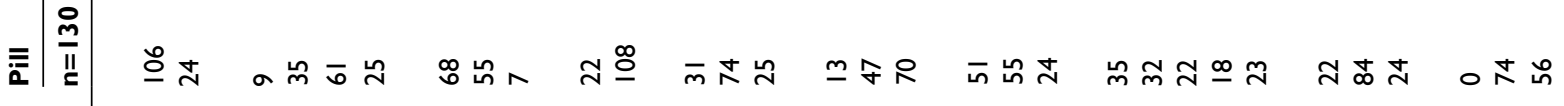
尔

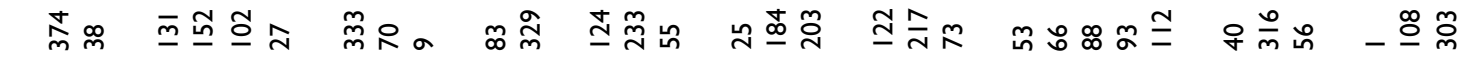

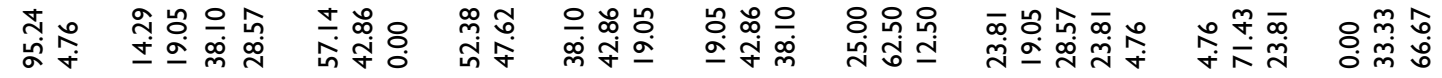

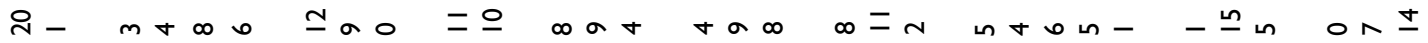

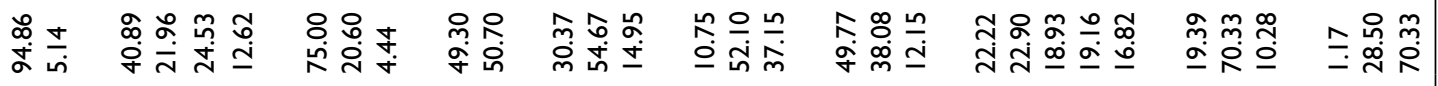

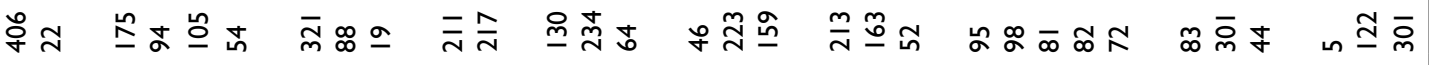

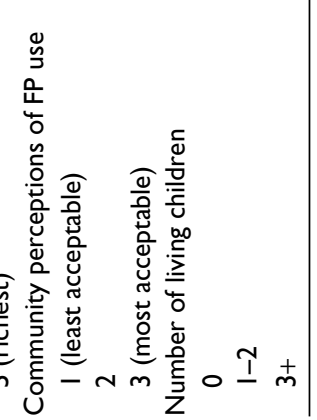


a traditional method, or condoms. The results displayed in Table 2 demonstrate that the largest proportion (38.30\%) of women who had no abortions reported use of no methods, as compared to women who had one or more induced abortions (18.97\%). The method most commonly used by women who had one or more induced abortions was condoms $(32.76 \%)$. Among the 116 women who had an induced abortion, only $6(5.17 \%)$ were using an implant or IUD, which collectively represented the long-acting reversible contraceptives (LARC). In comparison, a smaller proportion of women who had no induced abortions used LARC (2.47\%).

We assessed the bivariate results of history of induced abortion by study covariates. Based on the results presented in Table 3, we found that age, perceived access to contraceptives, contraceptive self-efficacy, and the number of living children all had statistically significant differences between no induced abortion and one or more induced abortions at $p<0.05$. Chi-square analysis results in Table 4 demonstrate a statistically significant difference in use of a modern contraceptive method for abortion history $(p<0.001)$. There were also significant differences $(p<0.05)$ between use of a modern method and all covariates measured, except for contraceptive self-efficacy $(p=0.210)$.

Table 5 displays results from the Poisson regression with robust standard errors, which demonstrate that women who had one or more abortions were 1.23 times more likely to use a modern contraceptive method as compared to those who never had an abortion (95\% CI: $1.10-1.36, p<0.001)$. Women who were older, reported having access to contraceptives, and had high community acceptability of FP use were also more likely to use a modern contraceptive method. The regression results also demonstrated that all categories of older age were significantly associated with using a modern method, as was having access to contraceptives (RR: $1.80, p<0.001)$ and high community acceptance of FP use (RR: $1.26, p=0.018$ ). Having a higher education was not significantly associated with use of a modern method, though having completed secondary school did result in a slightly higher likelihood of using a modern method (RR: $1.11, p=0.046)$. There was no statistically significant increase in the likelihood of using a modern method with having ever been married, having higher knowledge of contraceptives, possessing increased wealth, or having more living children $(p>0.05)$.

We then calculated the fully adjusted postregression predicted probabilities of using a modern contraceptive method for women who had no abortions and for those who had one or more abortions. Table 6 demonstrates that women who had never had an abortion had a $60 \%$ predicted probability of using a modern method (95\% CI: 0.59-0.61), while those who had one or more abortions had an $80 \%$ predicted probability of using a modern method (95\% CI: $0.76-0.84)$. The lack of overlap between the $95 \%$ CI of the two exposure groups indicates a significant difference in use of modern methods; as demonstrated in the regression results, women who had one or more abortions were more likely to use a modern method.

\section{Discussion and conclusion}

This study found that among women in Luanda, Angola, having had one or more induced abortions was significantly associated with current use of a modern contraceptive method. Various factors may explain this relationship, including greater exposure to modern methods and FP services among women who had induced abortions.

Prior studies conducted in various other settings have reported similar findings and potential reasons for this association. A systematic review of nine publications on low- and middle-income countries found that contraception uptake increased postabortion when there was access to a wide range of contraceptive methods and comprehensive sexual and reproductive health education. ${ }^{10} \mathrm{~A}$ study by Benson et al also found that offering a wide range of contraceptive methods at health clinics improved postabortion modern contraceptive uptake. ${ }^{23}$ Though we cannot make inferences on whether the subjects of our study were seen for PAC, this particular element of FP service provision has been shown to improve uptake of modern methods. ${ }^{24} \mathrm{~A}$ prospective intervention study in Zimbabwe also demonstrated an increased

Table 2 Percentage breakdown of type of contraceptive method by abortion history

\begin{tabular}{|c|c|c|c|c|c|c|c|c|c|c|c|c|c|c|c|c|}
\hline \multirow{2}{*}{$\begin{array}{l}\text { Contraceptive method } \\
\text { currently using }\end{array}$} & \multicolumn{2}{|c|}{ No method } & \multicolumn{2}{|c|}{ Traditional } & \multicolumn{2}{|c|}{ Condom } & \multicolumn{2}{|l|}{ Pill } & \multicolumn{2}{|c|}{ Injectable } & \multicolumn{2}{|c|}{ Implant } & \multicolumn{2}{|c|}{ IUD } & \multirow[t]{2}{*}{ Total } & \multirow[t]{2}{*}{$p$-value } \\
\hline & $n$ & $\%$ & $\bar{n}$ & $\%$ & $n$ & $\%$ & $n$ & $\%$ & $n$ & $\%$ & $\bar{n}$ & $\%$ & $\bar{n}$ & $\%$ & & \\
\hline Abortion & & & & & & & & & & & & & & & & $<0.001$ \\
\hline 0 & 406 & 38.30 & 20 & 1.89 & 374 & 35.28 & 106 & 10.00 & 128 & 12.08 & 16 & $|.5|$ & 10 & 0.94 & 1,060 & \\
\hline I+ & 22 & 18.97 & I & 0.86 & 38 & 32.76 & 24 & 20.69 & 25 & 21.55 & 5 & 4.31 & $\mathrm{I}$ & 0.86 & 116 & \\
\hline Total & 428 & 36.39 & 21 & 1.79 & 412 & 35.03 & 130 & 11.05 & 153 & 13.01 & 21 & 1.79 & 11 & 0.94 & 1,176 & \\
\hline
\end{tabular}

Abbreviation: IUD, intrauterine device. 
Table 3 History of induced abortion by study covariates

\begin{tabular}{|c|c|c|c|c|c|c|c|}
\hline \multirow[t]{3}{*}{ Covariates } & \multicolumn{7}{|l|}{ Abortion } \\
\hline & \multicolumn{2}{|l|}{0} & \multicolumn{2}{|l|}{$I+$} & \multicolumn{2}{|l|}{ Total } & \multirow[t]{2}{*}{ p-value } \\
\hline & $n=1,060$ & $\%$ & $n=116$ & $\%$ & $N=I, 176$ & $\%$ & \\
\hline Age (years) & & & & & & & $<0.001$ \\
\hline $15-19$ & 308 & 29.06 & 16 & 13.79 & 324 & 27.55 & \\
\hline $20-24$ & 282 & 26.60 & 27 & 23.28 & 309 & 26.28 & \\
\hline $25-34$ & 298 & 28.11 & 54 & 46.55 & 352 & 29.93 & \\
\hline $35+$ & 172 & 16.23 & 19 & 16.38 & 191 & 16.24 & \\
\hline Marital status & & & & & & & 0.064 \\
\hline Single & 717 & 67.64 & 66 & 56.90 & 783 & 66.58 & \\
\hline Married/cohabitating & 299 & 28.21 & 43 & 37.07 & 342 & 29.08 & \\
\hline Divorced/widowed & 44 & 4.15 & 7 & 6.03 & 51 & 4.34 & \\
\hline Access & & & & & & & 0.001 \\
\hline No & 335 & 31.60 & 20 & 17.24 & 355 & 30.19 & \\
\hline Yes & 725 & 68.40 & 96 & 82.76 & 801 & 69.81 & \\
\hline Contraceptive self-efficacy & & & & & & & 0.007 \\
\hline I (lowest self-efficacy) & 307 & 28.96 & 19 & 16.38 & 326 & 27.72 & \\
\hline 2 & 585 & 55.19 & 70 & 60.34 & 655 & 55.70 & \\
\hline 3 (highest self-efficacy) & 168 & 15.85 & 27 & 23.28 & 195 & 16.58 & \\
\hline Knowledge of contraceptives & & & & & & & 0.721 \\
\hline I (least knowledgeable) & 88 & 8.30 & 12 & 10.34 & 100 & 8.50 & \\
\hline 2 & 480 & 45.28 & 53 & 45.69 & 533 & 45.32 & \\
\hline 3 (most knowledgeable) & 492 & 46.42 & 51 & 43.97 & 543 & 45.17 & \\
\hline Education & & & & & & & 0.172 \\
\hline No education/primary school & 439 & 41.42 & 52 & 44.83 & 491 & 41.75 & \\
\hline Secondary school & 462 & 43.58 & 41 & 35.34 & 503 & 42.77 & \\
\hline University or higher & 159 & 15.00 & 23 & 19.83 & 182 & 15.48 & \\
\hline Wealth quintiles & & & & & & & 0.626 \\
\hline I (poorest) & 201 & 18.96 & 25 & 21.55 & 226 & 19.22 & \\
\hline 2 & 205 & 19.34 & 28 & 24.14 & 233 & 19.81 & \\
\hline 3 & 216 & 20.38 & 22 & 18.97 & 238 & 20.24 & \\
\hline 4 & 217 & 20.47 & 20 & 17.24 & 237 & 20.15 & \\
\hline 5 (richest) & 221 & 20.85 & 21 & 18.10 & 242 & 20.58 & \\
\hline Community perceptions of FP use & & & & & & & 0.429 \\
\hline I (least acceptable) & 144 & 13.58 & 16 & 13.79 & 160 & $13.6 \mid$ & \\
\hline 2 & 749 & 70.66 & 87 & 75.00 & 836 & 71.09 & \\
\hline 3 (most acceptable) & 167 & 15.75 & 13 & 11.21 & 180 & $|5.3|$ & \\
\hline Number of living children & & & & & & & 0.001 \\
\hline 0 & 6 & 0.57 & 0 & 0.00 & 6 & 0.51 & \\
\hline $1-2$ & 351 & 33.11 & 58 & 50.00 & 409 & 34.78 & \\
\hline $3+$ & 703 & 66.32 & 58 & 50.00 & 761 & 64.71 & \\
\hline
\end{tabular}

Abbreviation: FP, family planning.

uptake of modern methods and significantly fewer unplanned pregnancies when PAC FP was offered. ${ }^{9}$ PAC services may have been available and accessible to the respondents in this study, which led to the higher modern method use observed among women who had an abortion.

There was a lack of significant association between wealth and modern contraceptive use, which is inconsistent with what is known about wealth inequities and fertility practices. Higher socioeconomic status has been well documented as a predictor of contraceptive use in SSA. ${ }^{25,26}$ However, a recent study by Creanga et al found that wealth-related inequalities in contraceptive use have decreased in many countries in SSA, and reported that higher wealth status was associated specifically with long-acting contraceptive use. ${ }^{27}$ The discrepancy between our findings and the generally accepted knowledge surrounding socioeconomic status and contraceptive use may be explained by this diminishing gap, as many modern methods, namely, condoms, are becoming more widely available in the region. Furthermore, our models included abortion as an independent variable, which may be a stronger indicator of contraceptive use in similar populations; its presence may have diminished expected associations 
Table 4 Use of a modern contraceptive method by study covariates

\begin{tabular}{|c|c|c|c|c|c|c|c|}
\hline \multirow[t]{3}{*}{ Independent variables } & \multicolumn{7}{|c|}{ Abortion } \\
\hline & \multicolumn{2}{|l|}{ No } & \multicolumn{2}{|l|}{ Yes } & \multicolumn{2}{|l|}{ Total } & \multirow[t]{2}{*}{$p$-value } \\
\hline & $n=440$ & $\%$ & $n=736$ & $\%$ & $N=I, I 76$ & $\%$ & \\
\hline Abortion & & & & & & & $<0.001$ \\
\hline 0 & 417 & 94.77 & 643 & 87.36 & 1,060 & 90.14 & \\
\hline $1+$ & 23 & 5.23 & 93 & 12.64 & 116 & 9.87 & \\
\hline Age (years) & & & & & & & $<0.001$ \\
\hline $15-19$ & 178 & 40.45 & 146 & 19.84 & 324 & 27.55 & \\
\hline $20-24$ & 96 & 21.82 & 213 & 28.94 & 309 & 26.28 & \\
\hline $25-34$ & 110 & 25.00 & 242 & 32.88 & 352 & 29.93 & \\
\hline $35+$ & 56 & 12.73 & 135 & 18.34 & 191 & 16.24 & \\
\hline Marital status & & & & & & & $<0.001$ \\
\hline Single & 328 & 74.55 & 455 & 61.82 & 783 & 66.58 & \\
\hline Married/cohabitating & 93 & 21.14 & 249 & 33.83 & 342 & 29.08 & \\
\hline Divorced/widowed & 19 & 4.32 & 32 & 4.35 & 51 & 4.34 & \\
\hline Access & & & & & & & $<0.001$ \\
\hline No & 217 & 49.32 & 138 & 18.75 & 355 & 30.19 & \\
\hline Yes & 223 & 50.68 & 598 & 81.25 & 821 & 69.81 & \\
\hline Contraceptive self-efficacy & & & & & & & 0.210 \\
\hline I (lowest self-efficacy) & 134 & 30.45 & 192 & 26.09 & 326 & 27.72 & \\
\hline 2 & 240 & 54.55 & 415 & 56.39 & 655 & 55.70 & \\
\hline 3 (highest self-efficacy) & 66 & 15.00 & 129 & 17.53 & 195 & 16.58 & \\
\hline Knowledge of contraceptives & & & & & & & $<0.001$ \\
\hline I (least knowledgeable) & 47 & 10.68 & 53 & 7.20 & 100 & 8.50 & \\
\hline 2 & 229 & 52.05 & 304 & 41.30 & 533 & 45.32 & \\
\hline 3 (most knowledgeable) & 164 & 37.27 & 379 & 51.49 & 543 & 46.17 & \\
\hline Education & & & & & & & $<0.001$ \\
\hline No education/primary school & 216 & 49.09 & 275 & 37.36 & 491 & 41.75 & \\
\hline Secondary school & 171 & 38.86 & 332 & 45.11 & 503 & 42.77 & \\
\hline University or higher & 53 & 12.05 & 129 & 17.53 & 182 & 15.48 & \\
\hline Wealth quintiles & & & & & & & 0.010 \\
\hline I (poorest) & 98 & 22.27 & 128 & 17.39 & 226 & 19.22 & \\
\hline 2 & 101 & 22.95 & 132 & 17.93 & 233 & 19.81 & \\
\hline 3 & 85 & 19.32 & 153 & 20.79 & 238 & 20.24 & \\
\hline 4 & 83 & 18.86 & 154 & 20.92 & 237 & 20.15 & \\
\hline 5 (richest) & 73 & 16.59 & 169 & 22.96 & 242 & 20.58 & \\
\hline Community perceptions of FP use & & & & & & & $<0.001$ \\
\hline I (least acceptable) & 83 & 18.86 & 77 & 10.46 & 160 & 13.61 & \\
\hline 2 & 310 & 70.45 & 526 & 71.47 & 836 & 71.09 & \\
\hline 3 (most acceptable) & 47 & 10.68 & 133 & 18.07 & 180 & $\mid 5.31$ & \\
\hline Number of living children & & & & & & & 0.001 \\
\hline 0 & 5 & 1.14 & I & 0.14 & 6 & $0.5 \mathrm{I}$ & \\
\hline $1-2$ & 128 & 29.09 & 281 & 38.18 & 409 & 34.78 & \\
\hline $3+$ & 307 & 69.77 & 454 & 61.68 & 761 & 64.71 & \\
\hline
\end{tabular}

Abbreviation: FP, family planning.

between modern method use and other factors, including wealth, education, and marital status. Future studies should, therefore, consider incorporating questions about abortion history when possible in order to provide further data on its role in contraceptive uptake.

It is important to note that the most commonly selected modern method among women in our study sample who had one or more abortions was condoms. Though condoms are classified as a modern method and can be highly efficacious when used correctly, they have high failure rates and thereby a low effectiveness (up to 18 pregnancies per 100 women per year). ${ }^{28}$ It is, therefore, difficult to conclude that women in our study who were using a modern method were using one that would effectively prevent another unwanted pregnancy, particularly since condoms were the most highly used. In addition, our results demonstrated that women who had no 
Table 5 Relative risk of using a modern contraceptive method by abortion history

\begin{tabular}{|c|c|c|c|}
\hline \multirow{2}{*}{$\begin{array}{l}\text { Risk of using a modern } \\
\text { method, given abortion } \\
\text { history }\end{array}$} & \multicolumn{3}{|c|}{ Use of a modern method } \\
\hline & $\overline{\mathbf{R R}}$ & $95 \% \mathrm{Cl}$ & $p$-Value \\
\hline \multicolumn{4}{|l|}{ Abortion } \\
\hline 0 & I (ref) & - & - \\
\hline $1+$ & 1.23 & $1.10-1.36$ & $<0.001$ \\
\hline \multicolumn{4}{|l|}{ Age (years) } \\
\hline $15-19$ & I (ref) & - & - \\
\hline $20-24$ & 1.38 & $1.20-1.59$ & $<0.001$ \\
\hline $25-34$ & 1.31 & I.12-1.52 & 0.001 \\
\hline $35+$ & 1.32 & $1.12-1.57$ & 0.001 \\
\hline \multicolumn{4}{|l|}{ Marital status } \\
\hline Never married & I (ref) & - & - \\
\hline Ever married & 1.04 & $0.94-1.15$ & 0.467 \\
\hline \multicolumn{4}{|l|}{ Access } \\
\hline No & I (ref) & - & - \\
\hline Yes & 1.80 & $1.56-2.06$ & $<0.001$ \\
\hline \multicolumn{4}{|l|}{ Knowledge } \\
\hline I (least knowledgeable) & I (ref) & - & - \\
\hline 2 & 1.01 & $0.82-1.23$ & 0.956 \\
\hline 3 (most knowledgeable) & 1.15 & $0.94-1.40$ & 0.178 \\
\hline \multicolumn{4}{|l|}{ Education } \\
\hline No education/primary school & I (ref) & - & - \\
\hline Secondary school & 1.11 & $1.00-1.23$ & 0.046 \\
\hline University or higher & 1.07 & $0.94-1.22$ & 0.323 \\
\hline \multicolumn{4}{|l|}{ Wealth quintiles } \\
\hline I (poorest) & I (ref) & - & - \\
\hline 2 & 0.94 & $0.81-1.09$ & 0.428 \\
\hline 3 & 1.06 & $0.92-1.22$ & 0.451 \\
\hline 4 & 1.02 & $0.88-1.18$ & 0.776 \\
\hline 5 (richest) & 1.06 & $0.92-1.22$ & 0.446 \\
\hline \multicolumn{4}{|c|}{ Community perceptions of FP use } \\
\hline I (least acceptable) & I (ref) & - & - \\
\hline 2 & 1.12 & $0.95-1.33$ & 0.180 \\
\hline 3 (most acceptable) & 1.26 & $1.04-1.52$ & 0.018 \\
\hline \multicolumn{4}{|l|}{ Number of living children } \\
\hline 0 & I (ref) & - & - \\
\hline $1-2$ & 3.52 & $0.59-20.92$ & 0.167 \\
\hline $3+$ & 3.58 & $0.60-21.32$ & 0.162 \\
\hline
\end{tabular}

Abbreviations: FP, family planning; RR, relative risk.

abortions most commonly reported using no method, despite responding that they were sexually active and not actively trying to get pregnant. Several factors could influence women's strong preference for condoms among those who had an induced abortion and for lack of method use among those who did not. Misinformation or skepticism about certain methods can impede uptake of more effective contraceptives, namely, LARC. ${ }^{29,30}$ Furthermore, condoms are currently the most widely available FP method in Luanda, followed by the oral pill and injectable methods. ${ }^{14} \mathrm{FP}$ programs should focus on improving provision of LARC methods, particularly in the context of PAC services. Angola recently implemented
Table 6 Predicted probabilities of using a modern contraceptive method by abortion history

\begin{tabular}{llc}
\hline Currently using a modern method \\
\hline Abortion & $\begin{array}{l}\text { Adjusted }{ }^{\mathrm{a}} \text { predicted } \\
\text { probability }\end{array}$ & $\mathbf{9 5 \%} \mathbf{~ C l}$ \\
\hline 0 & 0.60 & $0.59-0.6 \mathrm{I}$ \\
$\mathrm{I}+$ & 0.80 & $0.76-0.84$ \\
\hline $\begin{array}{l}\text { Note: }{ }^{2} \text { Age, marital status, access, knowledge, education, wealth, community } \\
\text { perceptions, number of living children. }\end{array}$
\end{tabular}
perceptions, number of living children.

a PAC program that has improved postabortion contraceptive uptake, but the results of our study indicate a high need for supplies and training to offer methods postabortion that would be more effective and long term than condoms. ${ }^{31}$

Further research is needed to understand to what extent abortion influences contraceptive uptake in SSA, as well as how to tailor interventions to offer a wide variety of modern methods to populations that have limited access to FP care services and want to prevent unwanted pregnancies. This analysis provides insight into the relationship between past induced abortion and current contraceptive use, but prospective studies examining contraceptive use prior to and after an abortion would be more informative in understanding how abortion could directly influence women's contraceptive practices. ${ }^{32,33}$ These types of studies could provide information on whether women currently using modern methods changed their contraceptive method after terminating a pregnancy, and why they are selecting less effective modern contraceptives as opposed to LARC methods. Studies with larger sample sizes could potentially assess the association of past induced abortion with use of specific types of contraceptive methods or examine differences among women who had multiple abortions. This study sample did not have adequately large cell sizes ( $<10$ observations) to be able to make statistical inferences on these particular assessments. Ultimately, studies that are designed to assess the causal factors underlying the relationship between abortion and contraceptive use are needed for increasing uptake of modern methods in Angola.

A major limitation of our study is its cross-sectional design, which does not allow us to establish causality. It is unknown when in time the respondent began using her current contraceptive method, and therefore, whether she began using it after terminating her pregnancy or used it both before the induced abortion and continued using it afterward. Though modern methods prevent pregnancies at a greater rate than traditional methods, they may still fail and lead to an unintended pregnancy. We do not know if the respondent had an 
abortion as a result of method failure or because she was not using any contraceptive method. This does not allow us to establish temporality between the primary exposure and the outcome of interest and prevents us from being able to make causal inferences. However, this is likely not a major limitation due to the fact that in SSA, a vast majority of unintended pregnancies and subsequent induced abortions occur when a woman is not using any contraceptive method. ${ }^{34}$ Other limitations and potential sources of bias included that the study population consisted of women in the province of the capital city of Angola, which may not be generalizable to the rural or other urban areas of the country. In addition, there may have been information bias due to misclassification of study participants who reported using multiple contraceptive methods. Respondents were grouped into "no method/ traditional" and "modern" contraceptive methods based on the most effective method they were using at the time. This may not be reflective of the method they used most frequently, resulting in women who reported using both types of contraceptives being more frequently misclassified as using a modern method. This could lead to non-differential misclassification of the outcome, as it would have occurred independently of the exposure, and result in bias of the measure of association toward the null.

This study also had several strengths. There are, to date, no comprehensive reports containing information about abortion in the country of Angola. The Demographic and Health Survey for Angola includes information about FP and fertility but does not include nationwide abortion facts or statistics. ${ }^{12}$ It is difficult to get accurate abortion information because many abortions in SSA are performed illegally and women usually underreport abortion. ${ }^{35}$ The fact that our study was the first to collect data on abortion in Angola might indicate there was social desirability bias in our study, as some women may have been uncomfortable admitting they had terminated a pregnancy, either lawfully or otherwise. However, it is unlikely that social desirability bias influenced the reporting of modern method use since condoms and other modern contraceptives are not legally restricted in Angola. ${ }^{14}$ This would indicate that our observed association would not decrease if there were actually more induced abortions in our sample than reported, as the numbers would have presumably been distributed equally across the outcome variable categories.

Results from our study provide basic insight into Angolan women's contraceptive behavior and its relationship with the history of induced abortion. While some of the respondents' abortions occurred many years prior to the survey, the fact that $66 \%$ of reported abortions occurred within 5 years of the survey taking place indicates that the observed association was not solely based on the known improvements to access to contraceptives over the past two decades in Angola. ${ }^{36}$ These results contribute to the growing body of evidence on abortion and contraceptive use in a country with so little information on the topic. Data from this analysis can inform future studies that examine what aspects of abortion might influence use of modern contraceptives in Angola, with the intention of implementing these practices to increase uptake of more highly effective contraceptive methods.

\section{Acknowledgments}

We would like to thank Karen Weidert, MPH, for her assistance with language editing and proofreading. We would also like to thank Dr Mahasin Mujahid, $\mathrm{PhD}$, for her guidance and support during prior iterations of the analyses.

\section{Disclosure}

The authors report no conflicts of interest in this work.

\section{References}

1. Padmadas SS, Lyons-Amos M, Thapa S. Contraceptive behavior among women after abortion in Nepal. Int J Gynecol Obstet. 2017;127:132-137.

2. Sedlecky K, Stanković Z. Contraception for adolescents after abortion. Eur J Contracept Reprod Health Care. 2016;21:4-14.

3. Carvalho A, Laudari C, Marini M, Faundes A. Characteristics of contraceptive acceptors in Luanda, Angola. Afr J Fertil Sexual Reprod Heal. 1996;1:109-114.

4. Prata N, Bell S, Weidert K, Nieto-Andrade B, Carvalho A, Neves I. Varying family planning strategies across age categories: differences in factors associated with current modern contraceptive use among youth and adult women in Luanda, Angola. Open Access J Contracept. 2016;7:1-9

5. Lauro D. Abortion and contraceptive use in sub-Saharan Africa: how women plan their families. Afr J Reprod Health. 2011;15:13-23.

6. Cohen SA. Access to safe abortion in developing world: saving lives while advancing rights. 2012.

7. Benson J, Andersen K, Samandari G. Reductions in abortion-related mortality following policy reform: evidence from Romania, South Africa and Bangladesh. Reprod Health 2011;8:39.

8. Heikinheimo O, Gissler M, Suhonen S. Age, parity, history of abortion and contraceptive choices affect the risk of repeat abortion. Contraception. 2008;78:149-154.

9. Johnson BR, Ndhlovu S, Farr SL, Chipato T. Reducing unplanned pregnancy and abortion in Zimbabwe through postabortion contraception. Stud Fam Plann. 2002;33:195-202.

10. Rogers C, Dantas JAR. Access to contraception and sexual and reproductive health information post-abortion: a systematic review of literature from low- and middle-income countries. J Fam Plann Reprod Health Care. 2017;43(4):309-318.

11. Sharan M, Ahmed S, May J, Soucat A. Family planning trends in SubSaharan Africa: progress, prospects, and lessons learned. Yes Africa Can. 445, 2011.

12. Key Findings of the 2015-16 Angola IIMS. (Instituto Nacional de Estatística (INE), Ministério da Saúde (MINSA), Ministério da Planeamento e do Desenvolvimento Territorial (MPDT) and ICF, 2017).

13. Masangkay, N. Abortion Policies: Afghanistan to France. United Nations Publications, 2001. 
14. Nieto-Andrade B, Fidel E, Simmons R, et al. Women's limited choice and availability of modern contraception at retail outlets and publicsector facilities in Luanda, Angola, 2012-2015. Glob Health Sci Pract. 2017;5:75-89.

15. National Statistical Office - Angola [webpage on the Internet]. Available from: http://www.nber.org/africa/display/1095. Accessed April 13, 2018.

16. ICF International. Demographic and Health Surveys Methodology Questionnaires: Household, Woman's, and Man's. CA: ICF International; 2011.

17. Population Services International (2003). Project TRaC: Tracking Results Continuously. Retrieved September 15, 2017.

18. Hubacher D, Trussell J. A definition of modern contraceptive methods. Contraception. 2015;92:420-421.

19. Wealth-Quintile-Guide.pdf.

20. TRaC-Dashboard-Toolkit.pdf.

21. Zou G. A modified poisson regression approach to prospective studies with binary data. Am J Epidemiol. 2004;159:702-706

22. StataCorp. Stata Statistical Software: Release 14. College Station, TX: StataCorp LP; 2015.

23. Benson J, Andersen K, Brahmi D, et al. What contraception do women use after abortion? An analysis of 319,385 cases from eight countries. Glob Public Health. 2016;1-16.

24. Gallagher M, Chukmuwalu K, Baunach S. Uptake of Post-abortion Care (PAC) services and acceptance of post-abortion contraception in remote areas of Puntland, Somalia. Ann Glob Health. 2017;83:97.

25. Dias JG, de Oliveira IT. Multilevel effects of wealth on women's contraceptive use in Mozambique. PLoS One. 2015;10(3):e0121758.

26. WHO | Low Use of Contraception Among Poor Women in Africa: An Equity Issue [webpage on the Internet]. WHO Available from: http://www who.int/bulletin/volumes/89/4/10-083329/en/. Accessed April 13, 2018.
27. Creanga AA, Gillespie D, Karklins S, Tsui AO. Low use of contraception among poor women in Africa: an equity issue. Bull World Health Organ. 2011;89:258-266.

28. Guttmacher Institute (2016) [homepage on the Internet]. Contraceptive Use in the United States. Available from: https://www.gutt. Accessed September 15, 2017.

29. Kakaire O, Nakiggude J, Lule JC, Byamugisha JK. Post abortion women's perceptions of utilizing long acting reversible contraceptive methods in Uganda. A qualitative study. Open J Obstet Gynecol. 2014;04:1087.

30. Williamson LM, Parkes A, Wight D, Petticrew M, Hart GJ. Limits to modern contraceptive use among young women in developing countries: a systematic review of qualitative research. Reprod Health. 2009;6:3.

31. Bell S, Weidert K, Fraser A, Prata N. Health Facility Assessment Report: Cacuaco and Viana Municipalities. UC Berkeley Bixby Center: Angola Comprehensive Family Planning and Post-Abortion Care Project. 2013.

32. Borges ALV, OlaOlorun F, Fujimori E, Hoga LAK, Tsui AO. Contraceptive use following spontaneous and induced abortion and its association with family planning services in primary health care: results from a Brazilian longitudinal study. Reprod Health. 2015;12:94.

33. Prata N, Bell S, Holston M, Gerdts C, Melkamu Y. Factors associated with choice of post-abortion contraception in Addis Ababa, Ethiopia. Afr J Reprod Health. 2011;15:51-57.

34. Collumbien M, Gerressu M, Cleland J. Non-use and use of ineffective methods of contraception. 2004.

35. Induced Abortion Worldwide [webpage on the Internet]. Guttmacher Institute (2016). Available from: https://www.guttmacher.org/fact-sheet/ induced-abortion-worldwide. Accessed March 18, 2017.

36. Decker M, Constantine NA. Factors associated with contraceptive use in Angola. Afr J Reprod Health. 2011;15:68-77.
Open Access Journal of Contraception

\section{Publish your work in this journal}

Open Access Journal of Contraception is an international, peerreviewed, open access, online journal, publishing original research, reports, reviews and commentaries on all areas of contraception. In addition to clinical research, demographics and health-related aspects, the journal welcomes new findings in animal and preclinical studies

\section{Dovepress}

relating to understanding the biological mechanisms and practical development of new contraceptive agents. The manuscript management system is completely online and includes a very quick and fair peer-review system. Visit http://www.dovepress.com/testimonials.php to read real quotes from published authors. 